\title{
Customer Participation in the Specification of Services: The Role of Psychological Ownership and Participation Enjoyment
}

\author{
By Thomas Robbert, Lennart Straus, and Stefan Roth
}

The specification of services takes place at the pre-purchase stage, and thus this co-creation experience has important implications for service providers because it can influence customers' purchase intentions. One way to enhance the co-creation experience is through customer participation. Ample evidence indicates that participation positively influences post-service evaluation. While most research suggests economic reasons for this influence, the current work proposes that psychological reasons, such as participation enjoyment and psychological ownership, are more relevant. The findings reveal that customer participation leads to the development of psychological ownership even in early stages of the co-creation process. In addition, customers feel participation enjoyment during the service specification. The study shows that both constructs are stronger predictors for customers' purchase intentions than economic reasons. The paper disentangles different costs and benefits that derive through participation in service specification and elaborates on their relevance. This work enriches extant research by showing the influence of psychological benefits on the purchase of specified services.

\section{Introduction}

Many services must be specified to meet customer needs. For example, travel agents individualise their packages to deliver unique travel experiences, and kitchen or bathroom design services offer individualised solutions for each customer. The specification of a service occurs in an early participant interaction stage, which is often the first step in the value co-creation experience (Chan et al. 2010). In the specification, customers must detail their individual ideas and requirements, so as to determine the nature of service to be rendered, including price, design, quality, timing, or other service characteristics, in a close interaction with the service provider.

The specification of a service often occurs before the customer fully commits to paying for the service. As the provider has already invested a large number of resources in the service specification, losing customers after this stage is costly. This explains why service providers have an inherent interest in engaging customers as

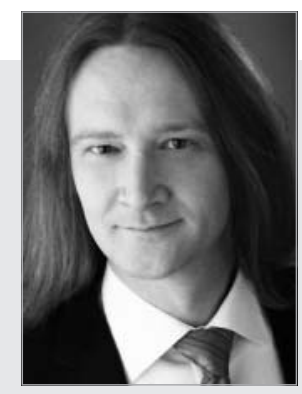

Stefan Roth is Professor for Marketing at University of Kaiserslautern, Gottlieb-DaimlerStrasse 42, 67663 Kaiserslautern, Germany, Phone: +49631 205 2929, Fax: +49 631205 3394, E-mail: roth@wiwi. uni-kl.de. 
partners of their personalised experiences (Dong 2015). The idea behind this rationale is that the experience during the service specification has important implications for customers' decisions to pay for the service, search for alternatives elsewhere or even postpone the purchase decision.

Ample evidence indicates that customer participation positively influences post-service evaluation. Research assumes that different constructs mediate the effect of participation on subsequent behavioural intentions. Most research in this area highlights economic reasons for this influence, suggesting that customer participation leads to increased service quality due to the fit of the offering with the customer needs (Bendapudi and Leone 2003; Chan et al. 2010; Simonson 2005). Yet participation is costly, in that consumers must invest intellectual energy, effort, and time for their participation (Franke and Schreier 2010). Summarizing the arguments, research largely confirms the co-creation of utilitarian or extrinsic value through customer participation. For customers, value creation is what really matters, and different constructs mediate the effect of their participation on their evaluations and purchase decisions (Chan et al. 2010; Yim et al. 2012). In particular, customers perceive the specification of offerings in terms of costs and benefits (Franke and Schreier 2010; Hunt et al. 2013). Literature has focused on the benefits, such as creation pride, and the costs, such as the invested intellectual energy, effort, and time, but has largely ignored the effect of non-conscious perceptions of the service offering on customers' decisions.

These effects of customer participation on psychological benefits and subsequent behavioural intentions are worthy of exploration. The questions that arise are: Which psychological benefits do customers derive through customer participation when specifying a service? What are the consequences for purchase intentions of a specified service? and What is the relative role of psychological benefits compared with economic benefits and perceived process costs in participation's effect on purchase intentions?

This work aims to answer these questions and to shed further light on the role of customer participation in the early co-creation stage of service specification. In doing so, the paper contributes to current literature in two ways. First, the paper elaborates on feelings of possession as a new and important psychological benefit to explain purchase intention of a specified service. We build on research on psychological ownership, which refers to a state of mind in which people feel as though an object belongs to them (Asatryan and Oh 2008; Jussila et al. 2015; Pierce et al. 2003). Empirical studies in service research have analysed the effect of touch on the perception of psychological ownership of an object (Brasel and Gips 2014; Peck and Shu 2009). In line with that research, the current work argues that the occurrence of psychological ownership can also be a consequence of customer participation (Asatryan and Oh 2008; Fuchs et al. 2010). Our study differs from previous research in that we show that possessiveness develops early in the co-creation process and that a long period of participation is not a pre-requisite.

Second, the paper elaborates on the relative importance of psychological ownership compared with other mediating constructs in explaining subsequent purchase intentions. Insights into these relationships are highly relevant for service providers whose goals are to design the specification of their services in a way that leads to a closed sale. Motivated by previous research, this study disentangles the effects of psychological ownership and participation enjoyment from economic benefit and perceived process costs. The results of our experimental study show that customer participation leads to psychological benefits, such as participation enjoyment and psychological ownership. Furthermore, we find that these benefits have a significant and positive impact on a customer's purchase intention. Most important, we find that the relationship between customer participation and psychological ownership, as well as its positive consequences for purchase intentions, is stronger than economic benefit and perceived process costs.

The remainder of this article proceeds as follows: First, we discuss the literature associated with the effect of customer participation and the related concept of engagement on customers' evaluation of the co-creation experience. Second, we conceptualise a research framework and develop four research hypotheses. Third, we discuss the methodology and present the results of the empirical study. Finally, we discuss the findings of the study and its limitations and provide avenues for further research.

\section{Theoretical background}

Chan et al. (2010, p. 49) define customer participation as a "behavioral construct that measures the extent to which customers provide/share information, make suggestions, and become involved in economic decision making". The concept focuses on actions that are elementary to service co-creation and can be discussed in the broader context of customer engagement. Brodie et al. (2011, p. 260) define customer engagement as a "psychological state that occurs by virtue of interactive, co-creative customer experiences with a focal agent/object (e. g., brand) in focal relationships".

Customer engagement is an all-inclusive approach with a broad scope. It applies an actor-to-actor perspective that is not limited to the interactions between customers and firms but also includes all kinds of actors in a service ecosystem (Brodie et al. 2011; Finsterwalder 2018; Vargo and Lusch 2016; Verleye et al. 2014). Customer engagement represents a customer's extra-role behaviour that is often voluntary, goes beyond particular transactions, and focuses on the interaction with firms and 
brands (Jaakkola and Alexander 2014; Van Doorn et al. 2010). This extra-role behaviour involves customers working to benefit the organization rather than acting out of self-interest (Ahearne et al. 2005). Engagement activities take place after the purchase and/or consumption experience (Dong and Sivakumar 2017).

Consistent with previous research, the domain of customer participation covers any customer behaviours that are for participating customers' own consumption and are part of the focal transactions. Beyond customer engagement, customer participation can even take place in pre-purchase/consumption experiences (Chan et al. 2010; Dong 2015; Yim et al. 2012). Dong and Sivakumar (2017) distinguish among three types of customer participation in the service specification: mandatory (e. g., providing information for a planned vacation trip), replaceable (e. g., choosing and evaluating suitable accommodations) and voluntary (e. g., researching travel tips to improve the tour design). Whereas mandatory customer participation can only be undertaken by the customer, replaceable customer participation can be undertaken by both the firm and the customer. Voluntary customer participation is only performed by the customer and is not necessarily required for the service. Thus, customer engagement is similar only to voluntary customer participation in that both represent voluntary behaviours and are not essential for service provision (Brodie et al. 2011). Yet engagement differs from mandatory or replaceable customer participation, which is the focus of this paper.

Evidence shows that customer participation positively affects service evaluations such as satisfaction (Driscoll 1978; Straus et al. 2016; Yim et al. 2012). So far, research has analysed customer participation mostly in terms of its impact on economic benefits. For example, Chan et al. (2010) show that the value derived from relational and economic benefits fully mediates the relationship between customer participation and satisfaction. Yet scant research has explored the psychological consequences of customer participation. Yim et al. (2012) extend the model of Chan et al. (2010) by integrating participation enjoyment as one relevant consequence of participation. In a similar vein, Atakan et al. (2014a) and Dong (2015) report positive effects of cognitive and emotional participation on customers' identification with the specified offering.

Similar explanations are available in the literature on customers' evaluation of mass-customisation offers and related self-design processes. Schreier (2006) reasons that customers enjoy the specification process and, in doing so, also develop feelings of pride. Franke and Schreier (2010) regard the specification process as fundamentally complex for customers which is experienced as process costs. The authors attribute this to the fact that participation in the specification of services is associated with strenuous, time-consuming problem-solving and selection processes. Franke et al. (2010) demonstrate that the self-design process generates feelings of accomplishment and thus argue that participation in specification results in an increased valuation of the finished product or service, as customers integrate their self into the specified offering. Atakan et al. (2014a, 2014b) assert that because customers bring their own ideas to suggestions in the specification, the product or service becomes a reflection of their personal values, attitudes and even identity. Consequently, customers feel psychologically attached to products adapted to their needs.

\section{Research framework}

We empirically elaborate on the effect of customer participation in the early participant interaction stage on the creation of economical and psychological benefits and compare their effect on subsequent purchase intentions. Drawing from previous findings of Chan et al. (2010) Yim (2012) and Atakan et al (2014a), we elaborate on four different components: economic benefit, perceived process costs, participation enjoyment and psychological ownership.

\subsection{Customer participation and economic benefit}

In the service specification, customers collect information, compare offers, deal with problems, and, finally, interact with the service provider's frontline staff to obtain what they want (Hsieh and Chang 2004). We argue that customers profit from their participation with increased economic benefit. We define an increased economic benefit as a better outcome of the core service, such as higher service quality, a service that better meets customer needs, or simply increased control of the service process. According to Simonson (2005), customer participation also makes the fit between the offer and the customer's preferences more transparent. Furthermore, research argues that customer participation contributes to improved technical quality through mechanisms of quality contribution and monitoring (Kellogg et al. 1997; LengnickHall 1996). Mustak et al. (2013) add that the central outcome addressed is customers' attainment of superior value, as the co-created offering better fits with their value creation processes.

We propose that by participating in the specification of services that goes beyond a mandatory level, customers have the chance to influence any decision, provide direct input and interact with the service provider in a way that allows achieving higher levels of customisation (Chan et al. 2010). By this, the customer ensures that the specified service matches his or her needs more appropriately. Research also argues that economic benefit is a key motivator for customers' purchase intentions (Shih 2012; Swait and Sweeney 2000). In line with this proposition, we expect low purchase intentions if customers judge a product as low in economic benefit and high purchase intentions in the opposite case. Therefore, we propose the following: 


\section{H1: A higher level of customer participation in the spec- ification of services leads to a higher economic ben- efit, which in turn has a positive effect on custom- ers' purchase intentions.}

\subsection{Customer participation and perceived process costs}

Participation in the specification of services requires customers to interact with the service provider's frontline employees. We propose that customer participation increases the effort through the non-monetary transaction costs associated with the service specification (Keh and Teo 2001; Shih 2012). These non-monetary transaction costs include customers' time and energy but also psychological costs (Xia and Suri 2014; Yen et al. 2004; Youngdahl and Kellogg 1997). Customers may experience these interactions as costly and view their participation as involving a high cognitive load (Franke and Schreier 2010).

Regarding the consequences of these invested efforts, research on the sunk-cost effect and escalation of commitment finds that individuals stick with decisions in which they have already invested resources (e. g., Arkes and Blumer 1985; Robbert et al. 2017; Roth et al. 2015). These invested resources are not necessarily limited to monetary investments but also include time and effort (Cunha and Caldieraro 2009). The basic idea underlying the sunk-cost effect comes from prospect theory (Kahneman and Tversky 1979). Building on this, Thaler (1985, 1999) argues that consumers track their investments on mental accounts. The created account remains open until the value of the investment is derived through its benefits. If an individual forgoes a pending benefit she will have to close the account "in the red", leading to a painful loss. Another psychological reason for the effect is the desire not to appear wasteful (Staw 1976, 1981). The sunk-cost effect is especially strong for individuals who tend to adhere to social rules and regulations. Thus, human personality traits such as conscientiousness and agreeableness also provide a theoretical explanation for the occurrence of the phenomenon (Fujino et al. 2016).

If customers go through the specification process and perceive their participation as costly, the perceived process costs are high. We argue that these costs are sunk and therefore result in a sunk-cost effect. After an investment is made, customers will have a feeling of wasted resources if a purchase does not result.

H2: A higher level of customer participation in the specification of services leads to higher perceived process costs, which in turn have a positive effect on customers' purchase intentions.

\subsection{Customer participation and participation enjoyment}

Value creation is embedded in personalised experiences (Prahalad and Ramaswamy 2004). An enjoyable ex- change experience can be created by customer participation (Dabholkar and Bagozzi 2002), as customers' role shifts from distanced spectators to co-producers of value (Deighton and Grayson 1995; Vargo and Lusch 2004). When people engage in activities for their own sake, they can derive enjoyment from their experience of participation (Payne et al. 2008). That is, people who actively engage in activities can thus derive enjoyment simply from their experience. Studies on self-service technologies also stress that the enjoyment customers obtain from their active role in service production explains why they prefer using such technologies (Dabholkar and Bagozzi 2002; Meuter et al. 2005).

Prior research has used enjoyment to capture the experiential nature of an activity and describes it as intrinsically rewarding (Kimiecik and Harris 1996). In addition, the concept of flow experience (Csikszentmihalyi 1975) offers a valuable framework to explain the effect of customer participation on enjoyment during the service process. Flow is an intrinsically motivated phenomenon that arises in conditions in which perceived challenges match the customer's skills and "the doing is the thing" (Csikszentmihalyi 1975, p. 37). It arises when goals exist and immediate feedback is given (Nakamura and Csikszentmihalyi 2002). In line with the argument of Yim et al. (2012), flow or an enjoyable, intrinsically rewarding experience can occur even in settings in which extrinsic rewards for themselves justify the participation. Tunder/ Irion (2007) see as prerequisites for experiencing flow in service processes that customers physically, mentally or socially participate, perceive a kind of subjective control over the process and receive immediate feedback on their participation. Allen and McGoun (2009) adds that even if the setting itself is not positive (e. g., financial services, health care), customers can still derive pleasurable experiences from participation.

A higher level of customer participation that goes beyond mandatory participation towards replaceable participation enables direct and active information exchange between customer and salesperson. This immediate feedback facilitates the flow experience of positive feelings (Nakamura and Csikszentmihalyi 2002). By contrast, when the service provider mainly performs the mandatory specification of the service, the customer is passive, so flow experiences do not evolve.

H3: A higher level of customer participation in the specification of services leads to higher participation enjoyment, which in turn has a positive effect on customers' purchase intentions.

\subsection{Customer participation and psychological ownership}

Finally, we argue that customer participation has a positive effect on the development of psychological ownership. When people experience a connection between themselves and various tangible and intangible targets, they gain a sense of ownership of them (Dittmar 1992). 
Psychological ownership refers to a cognitive-affective state in which "individuals feel as though the target of ownership (material or immaterial in nature) or a piece of it is "theirs"” (Pierce et al. 2001, p. 299).

For example, an engineer may feel ownership of a particular product design, an executive may feel ownership of a particular organizational strategic initiative or an employee may feel psychological ownership of the entire organization (Avey et al. 2009). Psychological ownership is distinct from related constructs with possessiveness as the primary distinguishing factor (Pierce et al. 2001). Whereas satisfaction refers to the evaluation of an object and the commitment to maintain a relationship with a provider, psychological ownership refers to the degree to which an object is considered "mine" (Van Dyne and Pierce 2004). Psychological ownership also differs from endowment, which is based on legal ownership. Under the endowment effect (Kahneman et al. 1991; Thaler 1980), individuals assign a higher value to a good in their possession than they are willing to pay for the same good they do not own. In contrast with the endowment effect, psychological ownership can arise without legal ownership of the target object (Shu and Peck 2011).

Psychological ownership develops because it satisfies the human needs for efficacy and effectance, self-identity, having a home, and stimulation. Individuals develop psychological ownership towards a target as they traverse the three routes to ownership: controlling the target, coming to intimately know the target and investing the self in the target (Pierce et al. 2001, 2003). Prior research has shown that the awareness of being the creator of a product results in enhanced evaluations of the object ("I designed it myself") in terms of willingness to pay (Franke et al. 2010). Jussila et al. (2015) propose that this then leads to a more favourable assessment of the target. In addition, Pierce and Jussila (2011) argue that the positive association between the self and the object for which ownership is felt results in behaviours that support and protect the target of ownership.

We argue that customer participation in the specification of services can facilitate the development of psychological ownership even in the early and often short stage of service specification. Higher participation enables a customer to gain intimate knowledge of the service, take control of its transformation and invest him- or herself into it. Consequently, customers experience the specified service as "theirs" and feel that they are responsible for it.

H4: A higher level of customer participation in the specification of services leads to higher psychological ownership for the specified offer, which in turn has a positive effect on customers' purchase intentions.

\section{Empirical study}

\subsection{Experimental design and procedure}

To test our hypotheses and find generalisable results for more than one special service, we used two contexts that fulfil two criteria. On the one hand, it is important that the characteristics and the way the service is provided are specified by the customer and the provider before purchase. Customers must have the opportunity to participate in the specification through physical, cognitive or emotional contributions. Customers should either play an active role, which is expressed primarily in voluntary participation, or merely give the provider the information required to prepare the offer. On the other hand, the services need to be available from different channels or providers. Thereby, the customers have the chance to take opportunistic action in which they purchase instead from a competing provider. The specification of a vacation trip in a travel agency meets these requirements. Customers can buy nearly standardised offers, such as package tours. However, they can also book travel packages in the form of structured individual trips adapted to their individual requirements. The preparation of an offer for a fitted kitchen in a studio is another context that meets these requirements. It is also possible to offer kitchens ranging from largely pre-fabricated to tailor-made kitchens. Customer participation can therefore also vary from passive to very active participation. Opportunistic action can also occur in both contexts.

To test our hypotheses, we designed a scenario experiment. We employed a between-subjects design, with the degree of customer participation (low vs. high) as the between-subjects factor. In the experiment, low customer participation is in line with mandatory customer participation (customers must provide necessary information to specify the service), while high customer participation is in line with replaceable customer participation (customer and service provider interact in the specification process). In both service contexts, participation in the specification process was low and rather passive in the lowparticipation condition. By contrast, participation in the high-participation condition was described as high and, therefore, time and energy consuming. Following the scenarios, participants indicated whether they intended to purchase the vacation trip or the kitchen, respectively. In addition, they expressed their agreement with statements that assessed the latent constructs and answered questions on control variables and demographics.

\subsection{Sample and data collection}

We recruited 347 participants and randomly assigned them to one of the conditions for both service contexts. The participants were mostly undergraduate students, $33.4 \%$ were women and the average age was 23.22 years $(\mathrm{SD}=5.04)$. Data collection took place in conjunction with an unrelated study in a computer lab at a German university. Participants received 10 EUR compensation for taking part in the study. 


\subsection{Measures and manipulation check}

To measure the constructs, we adapted established scales from marketing and organizational literature. All constructs were assessed on 7-point scales. The items were separately translated and adapted by members of the research team before final agreement was reached. Finally, we pretested the scenario and questionnaire. As the scales used were originally phrased in English, all items were translated into German and back-translated into English to ensure their validity. The appendix reports all the indicators.

For the manipulation check, we used Chan et al.'s (2010) five-item customer participation scale. We assessed the economic benefit and the participation enjoyment construct with Yim et al.'s (2012) and Chan et al.'s (2010) five- and four-item scales, respectively. We adapted the scale measuring perceived process costs from Franke and Schreier (2010). We adapted the two items of purchase intention from Grewal et al. (1998). For psychological ownership, we used indicators from Van Dyne and Pierce (2004). The scales fulfil the common quality criteria. Assessment of all the scales revealed that the factor reliability and average variance extracted (AVE) exceeded the cutoff criteria, and Cronbach's alpha was greater than .8 for all constructs. In addition, the AVE was greater than the squared multiple correlation for all latent constructs, thus establishing discriminant validity (Fornell and Larcker 1981). Tab. 1 provides the statistics of the key constructs.

\subsection{Analysis and results}

To test our hypotheses, we used a multiple mediation model, which involves simultaneous mediation by multiple variables. Preacher and Hayes (2008) recommend that testing such a model should involve assessing every specific indirect effect of customer participation through each mediator on purchase intention $\left(\mathrm{a}_{\mathrm{i}} \mathrm{b}_{\mathrm{i}}\right)$. In addition, an analysis of the total indirect effect, which is the aggregate mediating effect of all the mediators, is required. Thus, the total indirect effect is the sum of all specific indirect effects $\left(c^{\prime}=\Sigma a_{i} b_{i}\right)$. We used bootstrap analysis, a nonparametric sampling procedure, to test the significance of the indirect effects. In addition to the mediation, we included the service context and demographic variables as co-variates to account for population issues. To estimate the model, we used Hayes's (2014) PROCESS macro for SPSS. Fig. 1 illustrates the multiple mediation model of the effect of customer participation on purchase intention.

Before estimating the model, we compared the means of the two experimental conditions for perceived customer participation to establish successful manipulation. In the group with high customer participation, the mean values are significantly higher than those in the group with low customer participation $\left(\mathrm{M}_{\mathrm{CP} \text { high }}=6.27, \mathrm{SD}=.80 \mathrm{vs}\right.$. $\mathrm{M}_{\mathrm{CP}}$ $\left.{ }_{\text {low }}=3.69, \mathrm{SD}=1.67 ; \mathrm{F}(1,1345)=325.61, p<.01\right)$. To test our hypotheses, we analysed the impact of customer participation on the proposed mediators. In addition, we included service type, gender and age as co-variates. We found that all four constructs are significantly affected. As Tab. 2 illustrates, the standardised regression coefficient between customer participation and economic benefit is statistically significant $\left(\mathrm{a}_{1}=.752, p<.01\right)$, as is the

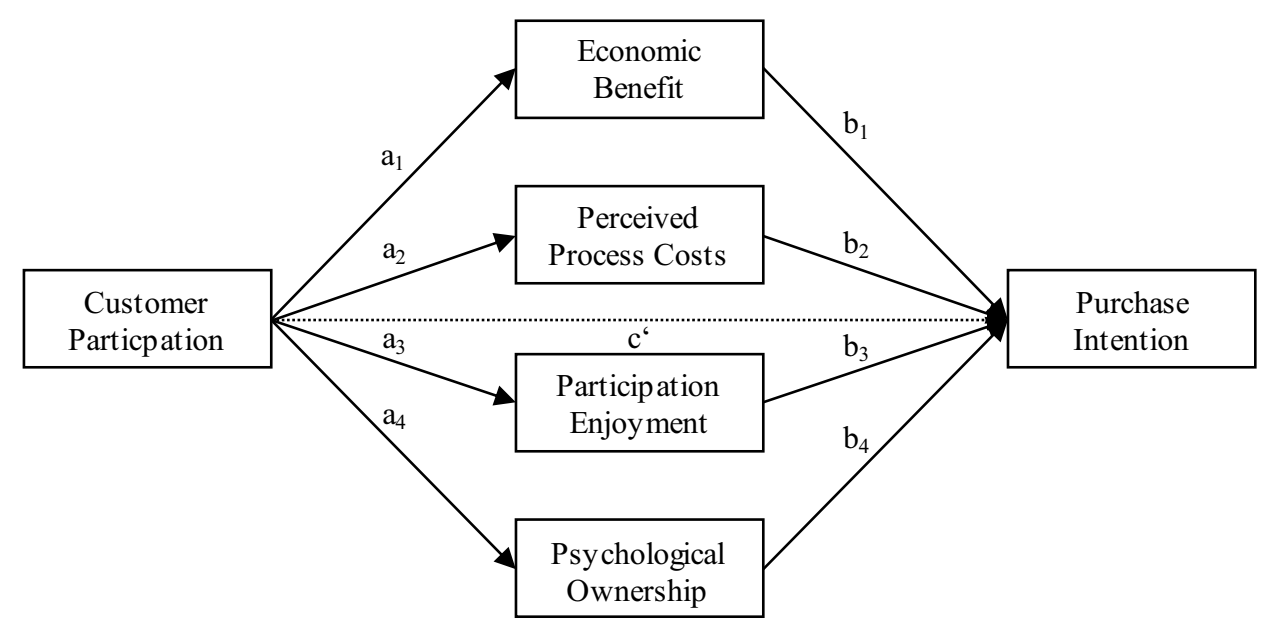

Fig. 1: Conceptual model

\begin{tabular}{llll}
\hline Construct & $\begin{array}{l}\text { Cronbach's } \\
\text { Alpha }\end{array}$ & $\begin{array}{l}\text { Factor } \\
\text { reliability }\end{array}$ & AVE \\
\hline Cutoff criterion & $>.7$ & $>.6$ & $>.5$ \\
\hline Economic benefit & .884 & .892 & .612 \\
Perceived process costs & .928 & .933 & .813 \\
Participation enjoyment & .912 & .941 & .791 \\
Psychological ownership & .893 & .901 & .753 \\
\hline
\end{tabular}

Tab. 1: Measurement model 


\begin{tabular}{|c|c|c|c|c|c|}
\hline & & & & \multicolumn{2}{|c|}{$95 \%$ BC CI } \\
\hline & Coeff. & SE & $\mathbf{t}$ & Lower & Upper \\
\hline$a_{1}: C P \rightarrow$ Economic benefit & $.752 * * *$ & .105 & 7.164 & .546 & .959 \\
\hline Service type & .048 & .107 & .448 & -.162 & .258 \\
\hline Gender & .004 & .110 & .034 & -.212 & .220 \\
\hline Age & -.008 & .010 & -.774 & -.028 & .012 \\
\hline$a_{2}: C P \rightarrow$ Perceived process costs & $.989 * * *$ & .100 & 9.897 & .793 & 1.186 \\
\hline Service type & -.122 & .102 & -1.198 & -.321 & .078 \\
\hline Gender & -.003 & .105 & -.027 & -.209 & .203 \\
\hline Age & -.002 & .097 & -.213 & -.021 & .017 \\
\hline$a_{3}: C P \rightarrow$ Participation enjoyment & $.939 * * *$ & .100 & 9.355 & .742 & 1.137 \\
\hline Service type & .146 & .102 & 1.436 & -.054 & .347 \\
\hline Gender & -.173 & .105 & -1.651 & -.380 & .033 \\
\hline Age & -.008 & .010 & -.824 & -.027 & .011 \\
\hline $\mathbf{a}_{4}: \mathbf{C P} \rightarrow$ Psychological ownership & $.813 * * *$ & .103 & 7.925 & .611 & 1.015 \\
\hline Service type & $-.206^{* *}$ & .104 & -1.976 & -.411 & -.001 \\
\hline Gender & .010 & .107 & .095 & -.201 & .221 \\
\hline Age & -.010 & .010 & -1.001 & -.030 & .010 \\
\hline $\mathrm{c}^{6}:$ Customer participation -> PI & .009 & .115 & .081 & -.216 & .235 \\
\hline $\mathrm{b}_{1}:$ Economic benefit $\rightarrow$ PI & $.156 * *$ & .062 & 2.503 & .033 & .279 \\
\hline $\mathrm{b}_{2}:$ Perceived process costs $\rightarrow$ PI & -.003 & .056 & -.055 & -.113 & .107 \\
\hline$b_{3}$ : Participation enjoyment $\rightarrow$ PI & $.287 * * *$ & .062 & 4.597 & .164 & .410 \\
\hline $\mathrm{b}_{4}$ : Psychological ownership $\rightarrow$ PI & $.327 * * *$ & .059 & 5.553 & .211 & .443 \\
\hline Service type & .039 & .095 & .411 & -.147 & .225 \\
\hline Gender & .048 & .096 & .495 & -.141 & .236 \\
\hline Age & .003 & .009 & .371 & -.014 & .021 \\
\hline
\end{tabular}

Notes: ${ }^{* * *} \mathrm{p}<.01 * * \mathrm{p}<0.5 . \mathrm{CP}=$ customer participation, $\mathrm{PI}=$ purchase intention, $\mathrm{BC} \mathrm{CI}=$ bias-corrected confidence interval, kitchen and male serve as reference category.

Tab. 2: Mediated regression

standardised regression coefficient between economic benefit and purchase intention $\left(b_{1}=.156, p<.05\right)$. In addition, customer participation significantly increases the perceived process costs $\left(\mathrm{a}_{2}=.989, p<.01\right)$. However, the non-significant standardised regression coefficient between perceived process costs and purchase intentions $\left(\mathrm{b}_{2}=.003, n s\right)$ reveals that there are no positive consequences for purchase intentions.

We find another significant and positive mediation for the relationship between customer participation and purchase intention through increased participation enjoyment $\left(\mathrm{a}_{3}=.939, p<.01 ; \mathrm{b}_{3}=.287, p<.01\right)$. Finally, customer participation has a large impact on psychological ownership $\left(\mathrm{a}_{4}=.813, p<.01\right)$ and, subsequently, on purchase intention $\left(b_{4}=.327, p<.01\right)$. In testing the direct relationship between customer participation and purchase intention, we find that the effect is small and nonsignificant ( $\left.c^{\prime}=.009, \mathrm{t}=.081, n s\right)$. We conclude that our reported constructs fully mediate the relationship.

Bootstrapping showed that for the indirect effect of economic benefit on purchase intention $\left(a_{1} b_{1}=.117\right)$, the bias corrected $95 \%$ confidence interval is entirely above zero (.013 to .252). We also find significant indirect effects for participation enjoyment $\left(a_{3} b_{3}=.269\right.$ (.116 to $.448)$ ) and psychological ownership $\left(a_{4} b_{4}=.266(.145\right.$ to .431)). Only the indirect effect of perceived process costs $\left(\mathrm{a}_{2} \mathrm{~b}_{2}=-.003(-.121\right.$ to .110$\left.)\right)$ is not significant. The results for the analysed co-variates show that only one relationship is influenced. Psychological ownership is significantly lower $(\beta=-.206, p<.05)$ in the travel context than in the kitchen context. Demographic variables are not significant for any relationships in our model. Thus, we find support for $H 1, H 3$, and $H 4$ but not for $H 2$.

\section{Discussion}

Our study provides empirical evidence for the premise that not only economic but also psychological benefits mediate the effect of customer participation on purchase intention. We find that customer participation largely increases the economic benefit of a specified service offering. This is in line with previous research showing that customer participation makes the fit between the offer and customers' preferences more transparent (Chan et al. 2010; Simonson 2005). We show that customer participation leads to specified services (e. g., an individualised travel plan) that suits individual customer needs. As a consequence, we find a positive relationship between customer participation in this pre-purchase situation and the intention to compensate the service provider through purchase. The results, however, also indicate that the influence of economic benefit is rather weak compared with the other constructs. This is surprising because the finding that a specified service matches customers' requirements does not fully explain why customers finally make a purchase decision.

In line with our assumptions, higher customer participation also increases the perceived process costs from timeand energy-consuming interactions with the service provider (e. g., Franke and Schreier 2010). We show that 
customers indeed perceive their effort as a cost component. The impact of customer participation on perceived process costs is the strongest relationship we find. We also expected to find a strong influence on subsequent purchase intentions due to a sunk-cost effect. In contrast with our hypothesis, we do not find a positive influence of perceived process costs on purchase intention. This result leads to the conclusion that though participation in the specification process is perceived as strenuous, tedious and time-consuming, it has no impact on customer repurchase intentions. We reason that this is because the invested resources are purely behavioural. The literature also documents inconclusive results for behavioural investments. For example, Cunha and Caldieraro (2009) demonstrate that sunk costs can also occur for invested time or effort, whereas Soman (2001) does not find a sunk-cost effect in these situations. In line with Soman (2001), we argue that investments of time or effort do not lead to a sunk-cost effect if consumers are not aware of the monetary equivalent of the investment. Thus, the effect may only derive from the perceived process costs if an hourly exchange rate or wage is provided or the opportunity costs are more salient.

The results also show that high customer participation increases participation enjoyment. This finding is in line with Yim et al. (2012), who argue that participation is an intrinsically rewarding experience. We find the positive influence to be stable in both service contexts. Regardless of whether the participation is performed in a more utilitarian context (kitchen studio) or a hedonic context (vacation trip), people enjoy the process of participation. Though not statistically significant, the results show that enjoyment is slightly higher when a vacation trip is specified according to customer needs.

Finally, our study provides empirical evidence that psychological ownership mediates the influence of customer participation on purchase intention in the service specification. In particular, we are the first to find evidence that customer participation leads to psychological ownership in the service specification. This finding is noteworthy for two reasons. First, the findings are in contrast with Pierce et al.'s (2003) contention that feelings of psychological ownership cannot develop in a rather short period. We extend and substantiate findings on the effects of customer participation found over a longer period. For example, Asatryan and Oh (2008) show that psychological ownership evolves over time between customers and their favoured restaurant. In our study, psychological ownership develops in the rather short co-creation experience of a service specification. Second, the size and the strength of psychological ownership are surprisingly high. We find that psychological ownership is the strongest predictor of customers' purchase intentions; it is even higher than what are typically considered "real" decision triggers, such as economic benefit. As a boundary condition, we find that the development of psychological ownership is dependent on the service context. Specifically, the results indicate that psychological ownership is stronger in the context of the specification of a kitchen than in a specified vacation trip. We reason that this is due to the special characteristics of services. Compared with the travel context, kitchen specification involves more creativity by customizing a tangible object. Thus, we underpin research showing that being the creator of a product enhances its evaluation (Franke and Schreier 2010; Franke et al. 2010).

\section{Managerial implications}

Our findings have important implications for service providers. We show that a specification process that only focuses on a high preference fit falls short. Service providers that neglect the influence of other benefits may face a situation in which the service offering perfectly matches the customer's need but the customer still chooses a competing service provider for final purchase. Service providers should allow customers to actively participate in the service specification process. For example, salespeople should actively involve customers in the offer development or specification. In doing so, the participation should exceed mandatory customer participation necessary to specify the service. Active participation means leading customers to a higher degree of participation by asking specification-oriented questions to enhance salespeople's understanding of their needs and wants and also to increase their participation enjoyment in the service specification. Salespeople should actively communicate that they desire and support customer participation. It is also important not only to promise a high degree of interaction but also to give the opportunity to do so. Participation is not necessarily limited to a personal interaction; technologybased customisation tools may elicit similar effects.

Service providers are likely to benefit the most from the positive effect of psychological ownership on purchase intention. As such, they should also integrate the positive effects of customer participation on psychological ownership in their communication strategy. It seems important to use ad claims such as "my individualised journey" or "my cruise" to foster ownership feelings, as some travel agents already do.

\section{Limitations and further research}

Our study is not without limitations and leaves room for future research endeavours. First, we elaborated on the effect of customer participation on psychological ownership in an experimental design employing scenarios. Although scenarios are widely used in marketing research, further research might elaborate on these effects in a real-world context. Examining the development of psychological ownership in a real service context would add external validity to our findings.

Second, our scenarios described only two service contexts. We chose common situations in the market and 
found that the results are context sensitive to the development of psychological ownership. Thus, further investigations should elaborate on other service industries to determine the extent to which the results are generalisable. In particular, it would be fruitful to investigate services with a negative framing, such as medical services. This could shed further light on the question if participation always leads to feeling of enjoyment.

Third, we measured psychological ownership as a construct without elaborating on its antecedents, which are likely to be the three routes to psychological ownership we specified previously. Yet a detailed understanding on how psychological ownership evolves during service specification processes is required to make it more manageable. In addition, we did not elaborate on individual boundary conditions of the effects. An important question, however, pertains to the moderating impact of personality traits on our proposed hypotheses. An integrated analysis of customer characteristics, such as self-efficacy, role identification or willingness to participate, could shed light on the boundary conditions for the discussed effects.

Finally, research effort might focus on the development of psychological ownership in other phases of the purchasing process. For example, it is likely that customers have already dealt with the service provider before the specification phase and thus may have already developed a psychological connection with the service before it has been specified. This argumentation may be valid not only for customised services but also for other types of products (e. g., when customers do not decide to buy a jacket, dress or pair of shoes directly after trying them on for the first time, they may still feel this connection). Research should therefore examine the extent to which psychological ownership can arise during the entire search process and how this affects the customer's decision-making process.

\section{Appendix}

\begin{tabular}{|c|c|c|}
\hline \multicolumn{3}{|c|}{ Customer Participation (Chan et al. 2010, p. 60) } \\
\hline CP_1 & $\begin{array}{l}\text { I spent a lot of time sharing information about my needs and opinions with the staff during } \\
\text { the planning of the vacation trip. }\end{array}$ & \multirow{5}{*}{$\begin{array}{l}\text { 7-point } \\
\text { Likert scale }\end{array}$} \\
\hline CP_2 & $\begin{array}{l}\text { I put a lot of effort in to expressing my personal needs to the staff during the planning of the } \\
\text { vacation trip. }\end{array}$ & \\
\hline CP_3 & I always provide suggestions to the staff for improving the vacation trip. & \\
\hline CP_4 & I have a high level of participation in the planning of the vacation trip. & \\
\hline CP_5 & I am very much involved in deciding how the vacation trip should be provided. & \\
\hline \multicolumn{3}{|c|}{ Participation Enjoyment (Yim et al. 2012, p. 136) } \\
\hline PartEnjoy_1 & I enjoy the planning of the vacation trip with my participation very much. & \multirow{4}{*}{$\begin{array}{l}\text { 7-point Likert } \\
\text { scale }\end{array}$} \\
\hline PartEnjoy_2 & The planning of the vacation trip with my participation is very enjoyable. & \\
\hline PartEnjoy_3 & The planning of the vacation trip with my participation can be described as fun. & \\
\hline PartEnjoy_4 & I take great pleasure in the planning of the vacation trip with my participation. & \\
\hline \multicolumn{3}{|c|}{ Economic Benefit (Chan et al. 2010, p. 60) } \\
\hline EcoB_1 & My participation helps me receive a higher quality vacation trip. & \multirow{5}{*}{$\begin{array}{l}\text { 7-point Likert } \\
\text { scale }\end{array}$} \\
\hline EcoB_2 & My participation helps me receive a more customized vacation trip. & \\
\hline EcoB_3 & My participation helps me receive a more professional vacation trip. & \\
\hline EcoB_4 & My participation helps me receive a more customized vacation trip. & \\
\hline EcoB_5 & My participation helps me receive less service failure. & \\
\hline \multicolumn{3}{|c|}{ Perceived Process Costs (Franke and Schreier 2010, p. 1025) } \\
\hline PPC_1 & Planning the vacation trip required much effort. & \multirow{3}{*}{$\begin{array}{l}\text { 7-point Likert } \\
\text { scale }\end{array}$} \\
\hline PPC_2 & Planning the vacation trip was exhausting. & \\
\hline PPC_3 3 & I perceived planning the vacation trip as "costly" (in terms of time and effort). & \\
\hline \multicolumn{3}{|c|}{ Psychological Ownership (Van Dyne and Pierce 2004, p. 449) } \\
\hline PsychOwn_1 & This is MY vacation trip. & \multirow{3}{*}{$\begin{array}{l}\text { 7-point Likert } \\
\text { scale }\end{array}$} \\
\hline PsychOwn_2 & I sense that this is MY vacation trip. & \\
\hline PsychOwn_3 & It is hard for me to think about this vacation trip as MINE. & \\
\hline \multicolumn{3}{|c|}{ Purchase Intention (Grewal et al. 1998, p. 51) } \\
\hline PurchInt_1 & The probability that I would consider buying this vacation trip is... & \multirow{2}{*}{$\begin{array}{l}\text { 7-point Likert } \\
\text { scale }\end{array}$} \\
\hline PurchInt_2 & The likelihood that I would purchase this vacation trip is... & \\
\hline
\end{tabular}

Appendix: Constructs and indicators 


\section{References}

Ahearne, M., Bhattacharya, C. B., \& Gruen, T. (2005). Antecedents and Consequences of Customer-company Identification: Expanding the Role of Relationship Marketing. Journal of Applied Psychology, 90(3), 574-585.

Allen, D. E., \& McGoun, E. G., (2002). Hedonic investment. Financial Services Review, 9(4), 389-403.

Arkes, H. R., \& Blumer, C. (1985). The Psychology of Sunk Cost. Organizational Behavior and Human Decision Processes, 35(1), 124-140.

Asatryan, V. S., \& Oh, H. (2008). Psychological Ownership Theory: An Exploratory Application in the Restaurant Industry. Journal of Hospitality and Tourism, 32(3), 363-386.

Atakan, S. S., Bagozzi, R. P., \& Yoon, C. (2014a). Consumer Participation in the Design and Realization Stages of Production: How Self-Production Shapes Consumer Evaluations and Relationships to Products. International Journal of Research in Marketing, 31(4), 395-408.

Atakan, S. S., Bagozzi, R. P., \& Yoon, C. (2014b). Make It Your Own: How Process Valence and Self-Construal Affect Evaluation of Self-Made Products. Psychology \& Marketing, 31(6), 451-468.

Avey, J. B., Avolio, B. J., Crossley, C. D., \& Luthans, F. (2009). Psychological Ownership: Theoretical Extensions, Measurement and Relation to Work Outcomes. Journal of Organizational Behavior, 30(2), 173-191.

Bendapudi, N., \& Leone, R. (2003). Psychological Implications of Customer Participation in Co-production. Journal of Marketing, 67(1), 14-28.

Brasel, S. A., \& Gips, J. (2014). Tablets, Touchscreens, and Touchpads: How Varying Touch Interfaces Trigger Psychological Ownership and Endowment. Journal of Consumer Psychology, 24(2), 226-233.

Brodie, R. J., Hollebeek, L. D., Juriæ, B., \& Iliæ, A. (2011). Customer Engagement: Conceptual Domain, Fundamental Propositions, and Implications for Research. Journal of Service Research, 14(3), 252-271.

Chan, K. W., Yim, C. K., \& Lam, S. (2010). Is Customer Participation in Value Creation a Double-Edged Sword? Evidence from Professional Financial Services across Cultures. Journal of Marketing, 74(3), 48-64.

Csikszentmihalyi, M. (1975). Beyond Boredom and Anxiety, San Francisco: Jossey-Bass.

Cunha Jr., M., \& Caldieraro, F. (2009). Sunk-Cost Effects on Purely Behavioral Investments. Cognitive Science, 33(1), 105-113.

Dabholkar, P. A., \& Bagozzi, R. P. (2002). An Attitudinal Model of Technology-Based Self-Service: Moderating Effects of Consumer Traits and Situational Factors. Journal of the Academy of Marketing Science, 30(3), 184-201.

Deighton, J., \& Grayson, K. (1995). Marketing and Seduction: Building Exchange Relationships by Managing Social Consensus. Journal of Consumer Research, 21(4), 660-676.

Dittmar, H. (1992). The Social Psychology of Material Possessions: To Have Is to Be, New York: St. Martin's Press.

Dong, B. (2015). How a Customer Participates Matters: "I Am Producing” Versus “I Am Designing”. Journal of Services Marketing, 29(6), 498-510.

Dong, B., \& Sivakumar, K. (2017). Customer Participation in Services: Domain, Scope, and Boundaries. Journal of the Academy of Marketing Science, 45, 944-965.

Driscoll, J. W. (1978). Trust and Participation in Organizational Decision Making as Predictors of Satisfaction. Academy of Management Journal, 21, 44-56.

Finsterwalder, J. (2018). A 360-degree View of Actor Engagement in Service Co-creation. Journal of Retailing and Consumer Services, 40, 276-278.

Fornell, C. \& Larcker, D. (1981). Evaluating Structural Equation Models with Unobservable Variables and Measurement Error. Journal of Marketing Research, 18, 39-50.
Franke, N., \& Schreier, M. (2010). Why Customers Value SelfDesigned Products: The Importance of Process Effort and Enjoyment. Journal of Product Innovation Management, 27, 1020-1031.

Franke, N., Schreier, M., \& Kaiser, U. (2010). The 'I Designed It Myself' Effect in Mass Customization. Management Science, 56, 125-140.

Fuchs, C., Prandelli, E., \& Schreier, M. (2010). The Psychological Effects of Empowerment Strategies on Consumers' Product Demand. Journal of Marketing, 74(1), 65-79.

Fujino, J., Fujimoto, S., Kodaka, F., Camerer, C. F., Kawada, R., Tsurumi, K., Tei, S., Isobe, M, Miyata, J., Sugihara, G., Yamada, M., Fukuyama, H, Murai, T., \& Takahashi, H. (2016). Neural Mechanisms and Personality Correlates of the Sunk Cost Effect. Scientific Reports, 6, 1-9.

Grewal, D., Monroe, K. B., \& Krishnan, R. (1998). The Effects of Price-Comparison Advertising on Buyers' Perceptions of Acquisition Value, Transaction Value, and Behavioral Intentions. Journal of Marketing, 62(2), 46-59.

Hayes, A. F. (2014). The PROCESS Macro for SPSS and SAS. Available at: http://www.processmacro.org/index.html, (last accessed: April 23, 2018).

Hsieh, A.-T., \& Chang, E.-T. (2004). The Effect of Consumer Participation on Price Sensitivity. Journal of Consumer Affairs, 38(2), 282-296.

Hunt, D. M., Radford, S. K., \& Evans, K. R. (2013). Individual Differences in Consumer Value for Mass Customized Products. Journal of Consumer Behavior, 12(4), 327-336.

Jaakkola, E., \& Alexander, M. (2014). The Role of Customer Engagement Behavior in Value Co-Creation: A Service System Perspective. Journal of Service Research, 17(3), 247-261.

Jussila, I., Tarkiainen, A., Sarstedt, M., \& Hair, J.F. (2015). Individual Psychological Ownership: Concepts, Evidence, and Implications for Research in Marketing. Journal of Marketing Theory \& Practice, 23(2), 121-139.

Kahneman, D., Knetsch, J. L., \& Thaler, R. H. (1991). Anomalies: The Endowment Effect, Loss Aversion, and Status Quo Bias. Journal of Economic Perspectives, 5(1), 193-206.

Kahneman, D., \& Tversky, A. (1979). Prospect Theory: An Analysis of Decision under Risk. Econometrica, 47(2), 263-291.

Keh, H. T., \& Teo, C. W. (2001). Retail Customers as Partial Employees in Service Provision: A Conceptual Framework. International Journal of Retail and Distribution Management, 29(8), 370-378.

Kellogg, D. L., Youngdahl, W. E., \& Bowen, D. E. (1997). On the Relationship between Customer Participation and Satisfaction: Two Frameworks. International Journal of Service Industry Management, 8(3), 206-219.

Kimiecik, J. C., \& Harris, A. T. (1996). What is enjoyment? A conceptual/definitional analysis with implications for sport and exercise psychology. Journal of Sport and Exercise Psychology, 18(3), 247-263.

Lengnick-Hall, C. A. (1996). Customer Contributions to Quality: A Different View of the Customer-Oriented Firm. Academy of Management Review, 21(3), 791-824.

Meuter, M. L., Bitner, M. J., Ostrom, A. L., \& Brown, S. W. (2005). Choosing among Alternative Service Delivery Modes: An Investigation of Customer Trial of Self-Service Technologies. Journal of Marketing, 69(2), 61-83.

Mustak, M., Jaakkola, E., \& Halinen, A. (2013). Customer Participation and Value Creation: A Systematic Review and Research Implications. Managing Service Quality, 23(4), 341-359.

Nakamura, J., \& Csikszentmihalyi, M. (2002). The Concept of Flow. In C.R. Snyder, \& S.J. Lopez (Eds.), Oxford Handbook of Positive Psychology, New York: Oxford University Press, 89-105.

Payne, A. F., Storbacka, K., \& Frow, P. (2008). Managing the Cocreation of Value. Journal of the Academy of Marketing Science, 36(1), 83-96.

Peck, J., \& Shu, S. B. (2009). The Effect of Mere Touch on Perceived Ownership. Journal of Consumer Research, 36(3), 434-447. 
Pierce, J. L., \& Jussila, I. (2011). Psychological Ownership and the Organizational Context, Cheltenham: Edward Elgar.

Pierce, J. L., Kostova, T., \& Dirks, K. (2001). Toward a Theory of Psychological Ownership in Organizations. Academy of Management Review, 26, 298-310.

Pierce, J. L., Kostova, T., \& Dirks, K. T (2003). The State of Psychological Ownership: Integrating and Extending a Century of Research. Review of General Psychology, 7, 84-107.

Prahalad, C. K., \& Ramaswamy, V. (2004). Co-creation Experiences: The Next Practice in Value Creation. Journal of Interactive Marketing, 18(3), 5-14.

Preacher, K. J., \& Hayes, A. F. (2008). Asymptotic and Resampling Strategies for Assessing and Comparing Indirect Effects in Multiple Mediator Models. Behavior Research Methods, 40(3), 879-891.

Robbert, T, Straus, L. \& Roth, S. (2017). Because It Was the First One - The Effect of Purchase Order on the Sunk-Cost Effect. In M. Büttgen (Ed.), Beiträge zur Dienstleistungsforschung, Wiesbaden, 23-39.

Roth, S., Robbert, T., \& Straus, L. (2015). On the Sunk-Cost Effect in Economic Decision-Making: A Meta-Analytic Review. Business Research, 8(1), 99-138.

Schreier, M. (2006). The Value Increment of Mass-Customized Products: An Empirical Assessment. Journal of Consumer Behaviour, 5(4), 317-327.

Shih, H.-P. (2012). Cognitive Lock-in Effects on Consumer Purchase Intentions in the Context of B2C Web Sites. Psychology \& Marketing, 29(10), 738-751.

Shu, S. B., \& Peck, J. (2011). Psychological Ownership and Affective Reaction: Emotional Attachment Process Variables and the Endowment Effect. Journal of Consumer Psychology, 21(4), 439-452.

Simonson, I. (2005). Determinants of Customers' Responses to Customized Offers: Conceptual Framework and Research Propositions. Journal of Marketing, 69(1), 32-45.

Soman, D. (2001). The Mental Accounting of Sunk Time Costs: Why Times Is Not Like Money. Journal of Behavioral Decision Making, 14(3), 169-185.

Staw, B. M. (1976). Knee-deep in the Big Muddy: A Study of Escalating Commitment to a Chosen Course of Action. Organizational Behavior and Human Performance, 16(1), 27-44.

Staw, B. M. (1981). The Escalation of Commitment to a Course of Action. Academy of Management Review, 6(4), 577-587.

Straus, L., Robbert, T., \& Roth, S. (2016). Customer Participation in the Customization of Services: Effects on Satisfaction and Behavioral Intentions. Journal of Business Market Management, 9(1), 498-517.

Swait, J., \& Sweeney, J. C. (2000). Perceived Value and Its Impact on Choice Behavior in a Retail Setting. Journal of Retailing \& Consumer Services, 7(2), 77-88.

Thaler, R. H. (1980). Toward a Positive Theory of Consumer Choice. Journal of Economic Behavior and Organization, 1(1), $39-60$.

Thaler, R.H. (1985). Mental Accounting and Consumer Choice. Marketing Science, 4 (3), 199-214.

Thaler, R.H. (1999). Mental Accounting Matters. Journal of Behavioral Decision Making, 12 (3), 183-206.

Tunder, R. \& Irion, T. (2007). Flow-Erleben bei persönlich erbrachten Dienstleistungen. Zeitschrift für Management, 2 (4), 352-372.

Van Doorn, J., Lemon, K. N., Mittal, V., Nass, S., Pick, D., Pirner, P., \& Verhoef, P. C. (2010). Customer Engagement Behavior: Theoretical Foundations and Research Directions. Journal of Service Research, 13(3), 253-266.

Van Dyne, L., \& Pierce, J. (2004). Psychological Ownership and Feelings of Possession: Three Field Studies Predicting Employee Attitudes and Organizational Citizenship Behavior. Journal of Organizational Behavior, 25(4), 439-459.

Vargo, S. L., \& Lusch, R. F. (2004). Evolving to a New Dominant Logic for Marketing. Journal of Marketing, 68(1), 1-17.
Vargo, S. L., \& Lusch, R. F. (2016). Institutions and Axioms: An Extension and Update of Service-Dominant Logic. Journal of the Academy of Marketing Science, 44(1), 5-23.

Verleye, K., Gemmel, P., \& Rangarajan, D. (2014). Managing Engagement Behaviors in a Network of Customers and Stakeholders: Evidence from the Nursing Home Sector. Journal of Service Research, 17(1), 68-84.

Xia, L., \& Suri, R. (2014). Trading Effort for Money: Consumers' Cocreation Motivation and the Pricing of Service Options. Journal of Service Research, 17(2), 229-242.

Yen, H. R., Gwinner, K. P., \& Su, W. (2004). The Impact of Customer Participation and Service Expectation on Locus Attributions Following Service Failure. International Journal Service Industry Management, 15(1), 7-26.

Yim, C., Chan, K. W., \& Lam, S. (2012). Do Customers and Employees Enjoy Service Participation? Synergistic Effects of Self- and Other-Efficacy. Journal of Marketing, 76(6), 121-140.

Youngdahl, W. E., \& Kellogg, D. L. (1997). The Relationship between Service Customers' Quality Assurance Behaviors, Satisfaction, and Effort: A Cost of Quality Perspective. Journal of Operations Management, 15, 19-32.

\section{Zusammenfassung}

Die Spezifizierung von Dienstleistungen erfolgt in vielen Fällen bereits vor dem Kauf, so dass die kundenseitige Erfahrung dieser Spezifizierungsphase von großer Bedeutung ist. Eine Möglichkeit, die Erfahrung möglichst positiv zu gestalten, ist die aktive Mitwirkung der Kunden am Spezifizierungsprozess. Es gibt zahlreiche Hinweise darauf, dass die Mitwirkung die Bewertung einer Dienstleistung positiv beeinflussen kann. Bisherige Beiträge führen überwiegend ökonomische Gründe für diese positiven Effekte an. Die vorliegende Untersuchung macht deutlich, dass psychologische Gründe, wie die erlebte Freude sowie das Entstehen von psychologischem Eigentum, bei der Spezifizierung von Dienstleistungen noch relevanter sind. Die Ergebnisse einer experimentellen Studie zeigen, dass die Mitwirkung zur Entwicklung von psychologischem Eigentum führt, bevor ein Kunde sich überhaupt für den Kauf der Leistung entschieden hat. Darüber hinaus demonstrieren die Ergebnisse, dass die Kunden Freude an dem Spezifizierungsprozess selbst empfinden. Beide Konstrukte sind dabei stärkere Prädiktoren für die Kaufabsichten der Kunden als bekannte ökonomische Gründe.

\section{Keywords}

Psychological Ownership, Customer Participation, Service Specification, Customer Engagement.

\section{Schlüsselwörter}

Psychologisches Eigentum, Kundenmitwirkung, Dienstleistungsspezifizierung, Customer Engagement. 